\title{
Connecting agents and artifacts in CSCL: Towards a rationale of mutual shaping
}

Citation for published version (APA):

Overdijk, M., Van Diggelen, W., Kirschner, P. A., \& Baker, M. (2012). Connecting agents and artifacts in CSCL: Towards a rationale of mutual shaping. International Journal of Computer-Supported Collaborative Learning, 7(2), 193-210. https://doi.org/10.1007/s11412-012-9143-2

DOI:

$10.1007 / \mathrm{s} 11412-012-9143-2$

Document status and date:

Published: 01/06/2012

Document Version:

Peer reviewed version

Please check the document version of this publication:

- A submitted manuscript is the version of the article upon submission and before peer-review. There can be important differences between the submitted version and the official published version of record. People interested in the research are advised to contact the author for the final version of the publication, or visit the DOI to the publisher's website.

- The final author version and the galley proof are versions of the publication after peer review.

- The final published version features the final layout of the paper including the volume, issue and page numbers.

Link to publication

\section{General rights}

Copyright and moral rights for the publications made accessible in the public portal are retained by the authors and/or other copyright owners and it is a condition of accessing publications that users recognise and abide by the legal requirements associated with these rights.

- Users may download and print one copy of any publication from the public portal for the purpose of private study or research.

- You may not further distribute the material or use it for any profit-making activity or commercial gain

- You may freely distribute the URL identifying the publication in the public portal.

If the publication is distributed under the terms of Article 25fa of the Dutch Copyright Act, indicated by the "Taverne" license above, please follow below link for the End User Agreement:

https://www.ou.nl/taverne-agreement

Take down policy

If you believe that this document breaches copyright please contact us at:

pure-support@ou.nl

providing details and we will investigate your claim.

Downloaded from https://research.ou.nl/ on date: 26 Apr. 2023 


\title{
Q1 Connecting agents and artifacts in CSCL: Towards
} a rationale of mutual shaping

\author{
Maarten Overdijk • Wouter van Diggelen • \\ Paul A. Kirschner • Michael Baker
}

Abstract Studying how collaborative activity takes shape interactionally in the context of technological settings is one of the main challenges in the field of ComputerSupported Collaborative Learning (CSCL). It requires us, amongst other things, to look into the 'black box' of how technical artifacts are brought into use, or rather, how they are attuned to, interacted with, and shaped in various and varied practices. This article explores the establishment of a purposeful connection of human agents and technical artifacts in CSCL, that we call 'the agent-artifact connection'. In order to contribute to a grounded conception of this connection, we reviewed three theoretical positions: affordance, structures and instrument. Although these three positions differ in how they conceptualise the connection, they share the assumption that a technical artifact carries a potential for action that becomes available when artifact and agent connect, and that the availability of action opportunities is relative to the ones who interact with the artifact. In this article, we map out the conceptual and methodological implications for each of the positions. We argue that the rationale of 'shaping' collaborative interactions that underlies a part of CSCL research should be replaced by a rationale of 'mutual shaping' of human agents and technical artifacts.

Keywords Affordance $\cdot$ Agent-artifact connection $\cdot$ Instrument $\cdot$ Mutual shaping $\cdot$ Structures

M. Overdijk (凹)

Q4 Independent researcher, Nieuwstraat 47, $2312 \mathrm{KA}$, Leiden, The Netherlands e-mail: maartenoverdijk@gmail.com

W. van Diggelen

Research Centre Learning in Interaction, Utrecht University, Utrecht, The Netherlands

\section{P. A. Kirschner}

Q3 Centre for Learning Sciences and Technologies (CELSTEC), Open University, Heerlen, The Netherlands 
The main focus in the CSCL research community is on how people learn in the context of collaborative activity and how technological settings that support this activity can be designed and evaluated. The rationale that often - implicitly - underlies such support is as follows: a technical artifact imposes certain constraints and makes a range of action opportunities available to a group of learners. Use of the artifact within a script or 'scenario' shapes collaborative interactions between the learners according to the designers' intentions (Baker and Lund 1997; Jermann and Dillenbourg 2003; Kollar et al. 2006; Fischer et al. 2007). This rationale of 'shaping' collaborative interactions may suggest that the effects of a technical artifact on collaboration could be predicted rather straightforwardly, and that learners could readily engage in more productive interactions. However, it would be an oversimplification to speak of 'effects' or 'properties' of a technical artifact, as if these are stable characteristics that are generalizable over different groups or settings. Enactment of a script is always to some extent unpredictable (Dillenbourg and Tchounikine 2007) and artifacts can be appropriated in unexpected ways (Overdijk and Van Diggelen 2008; Dwyer and Suthers 2006). It is important to realise that the design of technological settings can only be indirect, in the sense that technological settings establish preconditions for educational opportunities, but do not causally determine those activities, or their attendant learning outcomes (Oliver 2011; Stahl and Hesse 2006; Jones et al. 2006). Studying how collaborative activity takes shape interactionally in the context of these technological settings is one of the main challenges in the field. It requires us to look into the 'black box' of how technical artifacts are brought into use by learners, or rather, how they are attuned to, interacted with, and shaped in various and varied practices.

In its general definition, technology refers to ensembles of technical artifacts, activities or processes, and practical knowledge (MacKenzie and Wajcman 1985). Educational technology, following this definition, is a composite entity that consists of learner(s) and $\operatorname{artifact}(\mathrm{s})$ as instantiated in the learning activity. It does not exist independent of its use (LeBaron 2002). Rather, it is constructed in activities where learners orient themselves to, and make sense of the tools and artifacts they are presented with (Stahl et al. 2006). Educational technology, thus, emerges from an interaction of learners and technical artifacts and is shaped by both. Following this line of reasoning, the rationale of 'shaping' collaborative interactions that underlies a part of CSCL research should be replaced by a rationale of 'mutual shaping' of agent and artifact. In order to arrive at a grounded conception of what we call 'the agent-artifact connection', as several people have already argued in this field of research (e.g., Oliver 2011; Bonderup Dohn 2009; Overdijk and Van Diggelen 2008; Jones et al. 2006), it is necessary to investigate theoretical issues and refine theoretical perspectives about this connection, specific to our field (Stahl and Hesse 2006, 2010).

A relation is an emergent property of the interaction of two or more parts in a system that connects these parts as being and working together. A relational perspective on technology specifies the nature of such a 'functional' connection of human agents and technical artifacts. It specifies, for example, how a purposeful connection between agent and artifact is established, and how this connection is managed among multiple agents. In this article we review three positions that concern this connection of technical artifacts and the people who use them. These positions adhere to distinct strands of theory, namely affordances (Gibson 1979), structuration theory (Giddens 1986), and instrumental genesis (Rabardel 1995). Each 
of these positions has gained considerable influence in studies of computer-supported collaborative learning, sometimes through reworking of original concepts. Although the three positions differ from each other in how they conceptualise the agent-artifact connection, they share the assumption that a technical artifact carries a potential for action that becomes available when the artifact and the human agent connect, and that the availability of action opportunities is relative to the needs, abilities or intentions of the one(s) who interact (s) with the artifact. Each of the three positions awards some degree of influence to both agent and artifact in how their connection takes shape.

We map out for each of the positions - affordance, structures and instrument - some conceptual and methodological implications for studying collaboration in technological settings. Our review is driven by the following questions: to what extent do these positions allow us to describe how the agent-artifact connection is established and managed in collaborative activity? And to what extent do they allow us to describe a mutual shaping the establishment of the connection wherein both agent and artifact have an influence? It is our aim to contribute to the debate as it takes shape in our community (Oliver 2011; Bonderup Dohn 2009; Overdijk and Van Diggelen 2008; Jones et al. 2006; Dwyer and Suthers 2006; Suthers 2006; LeBaron 2002) by drawing up parallels between the positions of affordance, structures and instrument. Our review of the individual positions is therefore concise. Throughout our discussion we use observations from a specific case study - of how a multi-user workspace was brought into use in a collaborative planning activity - as a reference to illustrate our points.

The planning case was carried out within a secondary vocational school, with a class of students at third year level (in a 4-year program), aged 14-15 (Overdijk 2009). Over the duration of the school year these students had to work on several projects, in groups of three. With each project the students were presented with a syllabus that contained a series of assignments. At the start of their project they were expected to construct a plan that would describe in detail for each day of the project the tasks that had to be carried out. The students were accustomed to first study the assignments in the syllabus, sketch out an initial plan with paper and pen, and then draw up a final plan in a computer program - either on a spreadsheet or word processor. Some groups, as a convention, contributed simultaneously to the paper and pen representation of their project plan, while others took turns, or worked from a distribution of roles whereby one of them would manipulate the artifact, and the others would comment and contribute to the discussion. For this study, the groups were invited to construct their project plan in a shared workspace called Digalo (described in the next section, see also e.g. Muller Mirza et al. 2007). The students had no prior experience with this type of workspace technology, and they were provided with limited instructions. Their experience with online synchronous interaction pertained mostly to chat. First, we observed the 'regular' planning activity whereby we made field notes in the classroom and collected the final project plans. Then we observed how the shared workspace was brought into use in the activity, whereby the system logged all interaction data.

In our experience, this case is exemplary for the type of intervention that is common in CSCL: a technical artifact is introduced in a classroom and learners are invited to bring the artifact into use in the learning activity. Their utilization of the artifact takes place against the background of how they would 'normally' do things, that is, without the computer support. The artifact is embedded in a script that specifies instructions but there's no single best way 
of doing things. The students have to make sense of the artifact they are presented with and jointly organize a productive use.

\section{Affordance}

The first strand of theory that we review centres on the concept of affordance (originally formulated in Gibson 1979; later interpreted and reworked most famously in Norman 1988, 1999; and also, for example, Gaver 1991, 1996; Hartson 2003; Chemero 2003; Turner 2005). The concept of affordance proposes that surfaces in the material environment embody specific opportunities for action that become available to the acting agent. These opportunities enable a functional coupling between the agent and his or her environment. The affordance, in the context of ecological perception in which it was initially developed, describes the way in which an animal picks up information from the environment as it moves through its natural surroundings. Later, the concept of affordance was extended to describe interactions with everyday cultural artifacts, such as the computer (Norman 1988, 1999). The notion of 'technology affordance' (Gaver 1991), understood as a dispositional action opportunity in technological settings, underlies several studies in CSCL research (e.g. Suthers 2006; Kirschner et al. 2004). But to what extent is the idea of (technology) affordance actually useful in explaining the agent-artifact connection in collaborative activity? We first turn briefly to affordance as it was originally formulated by Gibson (1979), reviewing some of the critiques that have been posited against it (see for example Turner 2005; Rappert 2003; Hutchby 2001), and then reflect briefly on technology affordance in its basic form (Norman 1988, 1999).

The basic definition of affordance is familiar to many in the CSCL community. Still, it serves our purpose to provide a brief but precise reading of the original concept. The affordance of an object refers to the opportunities for action carried by this object in relation to the perceiver of the object. The affordance is relational: it is seen as a property of the connection of the agent and the object. As such, as Gibson (1979) points out, it is both environmental and behavioural, both physical and psychical, but it cannot be reduced to either of these constitutive parts. This relational nature of affordance is grounded in five premises. The opportunities for action that become available through some object in the environment to some agent are relative to the needs of that agent (premise 1). An object reflects certain opportunities for action to one agent, while another agent may perceive other opportunities, depending on his or her needs. The concept of affordance is based on principles of direct perception. The information that is available through affordances is directly available to the perceiver, and is not based on any higher-level cognitive processing (premise 2). There is, in other words, no interpretation or mediation by symbols or rules involved in the perception of an affordance. Instead, the functional coupling of agent and object is 'natural', and governed by ecological laws (Shaw 2003) (premise 3). Moreover, affordances are not only directly perceived, they are also translated non-reflectively into action through what is called the 'perception-action loop' (premise 4). Finally, affordances are perceptual 'invariants', that is, they are fixed properties of the perceived stimulus (premise 5). Gibson emphasises this fixed nature by stating that "The affordance of something does not change as the need of the observer changes. The observer may or may not perceive or attend to the affordance, according to his needs, but the affordance, being invariant, is always there to be perceived" (Gibson 1979, p. 139). What may be perceived by the agent, in other words, remains unchanged, whether the agent perceives it or not. Turner (2005) summarises: "An affordance thus exists, whether it is perceived or used or 
not, furthermore it may be detected and used without explicit awareness of doing so" (p. 790).

In its original form, "affordance" is a thought-provoking concept that helps to create sensitivity with respect to the complexity of the agent-artifact connection. However, in this form, it has also limitations (e.g. Stoffregen 2004; Shaw 2003) and is not, for example, tailored to understanding collaboration in technological settings. To illustrate this, let us consider the introduction of the shared workspace in the planning activity.

The shared workspace (Fig. 1) is a multi-user platform designed to support joint activity in face-to-face settings. The members of a group sit around a table, each behind his or her own workstation - preferably a lap- or tabletop - and manipulate a shared representation on screen, while they can also communicate (non) verbally. The three main features of the workspace are a drawing space, a notation scheme that supports specific communicative acts, and simultaneous access. A participant selects a contribution card from the notation scheme and adds it to the drawing space. That participant can then add a textual label to the title space of that card. By double-clicking on the card a comment window appears, where the contribution can be further elaborated. Participants can produce contributions to the drawing space in parallel. Cards that are placed in the drawing space can be linked to other cards. For the planning case, the notation scheme was designed to specify parts of the plan, that is, tasks, duration and outcome. It also contained a predefined time structure: ten columns representing the 10 days of the project.

The shared workspace allowed the groups to jointly construct a representation of their plan in the drawing space, and to discuss this plan face-to-face as well. In terms of affordances, the workspace made certain action opportunities available. For example, it allowed contributions to the drawing space to be made simultaneously. Group members, however, could also contribute by taking turns. Whether or not the students perceived and

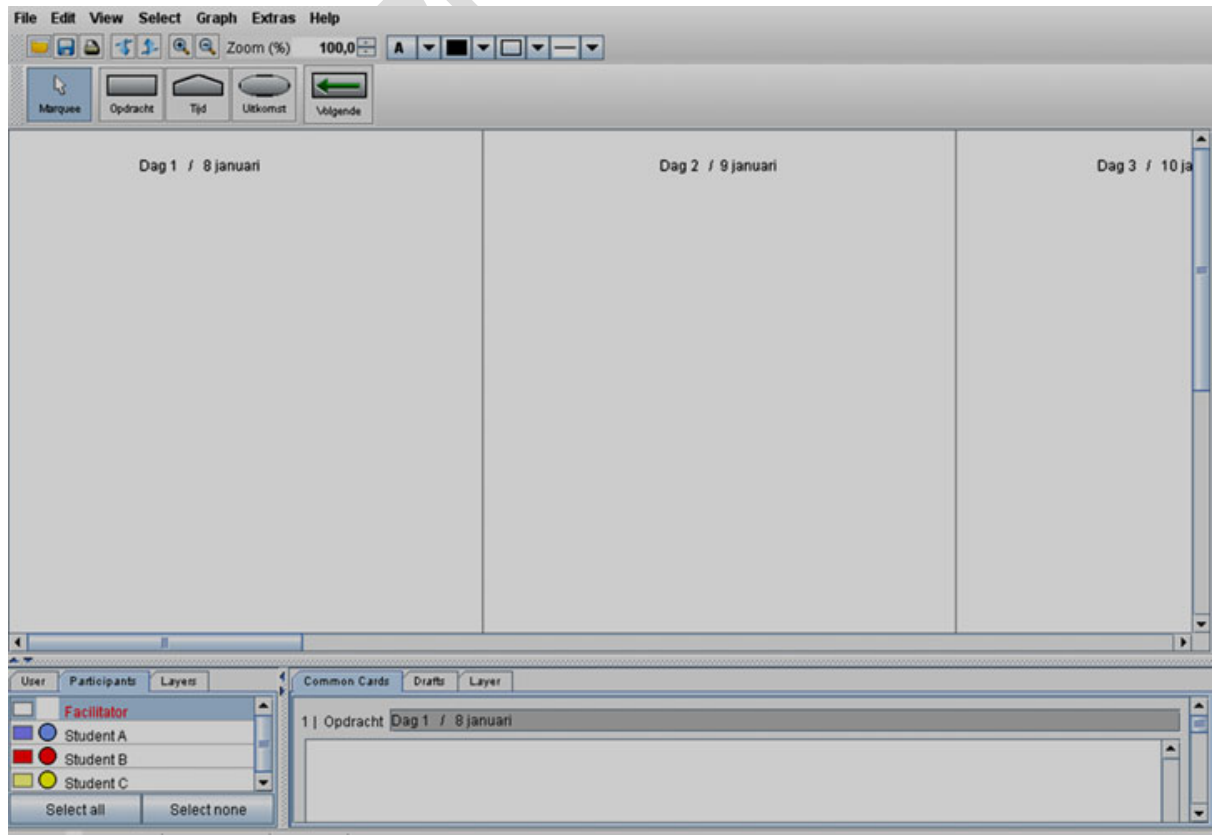

Fig. 1 Shared workspace with notation scheme and first three of the predefined columns 
used the opportunity to contribute simultaneously to the drawing space - 'the affordance of simultaneity' - depended not only on the opportunity being there but also on the students' expectations and experiences with previous collaborations. Some students in our case perceived and used the opportunity to contribute to the workspace by taking turns. Others assigned the role of typing and submitting contributions to one of the group members, while the others refrained themselves from contributing to the workspace directly. For some groups, these enactments were in fact near to their 'regular' way of plan construction, that is, with a sheet of paper and a pen. In other words, the opportunities for collaboration that became available via the workspace, those that were perceived and used, were relative to the students that work with it - within the set of constraints that were produced by the workspace.

So far so good. But can it be said that the opportunities that were enacted by the students were also directly perceived by them? This is difficult to determine from our observations. What we can establish, however, is that the action opportunities were not translated non-reflectively into action. Not in all cases anyway. The workspace is a flexible artifact whereby multiple opportunities may coexist at a given time. Collaboration in the workspace, therefore, requires a certain degree of coordination. Our observations, like other studies of similar workspaces (e.g. Baker et al. 2012; Overdijk and Van Diggelen 2008), point out that some groups go through a phase of negotiation in order to arrive at some shared convention on how to utilize the artifact. Thereby it is possible and sometimes likely that certain ways of doing - such as a specific distribution of roles between group members - are transposed. This does not appear to be a matter of ecological law but rather one of cultural rule or convention.

In thinking of Gibson's theory of affordance two questions come to mind. If affordances are directly perceived and realised in action, without mental representation, how do the conventions and rules that govern human activity tie in? How does a rule become a rule? Furthermore, if affordances are directly perceived, although they may provide different action opportunities to different participants in the activity, how is an effective realisation of opportunities achieved and coordinated? Both questions concern the way in which affordances are related to the social and cultural context in which artifacts are brought into use. Although we may assume a generally shared frame of reference in the use of such everyday things as a hammer or a chair, in other cases such a shared frame of reference cannot be assumed (Rappert 2003). Many artifacts that we find in technological settings for collaboration cannot be considered as everyday things: they are highly complex artifacts whose use is more often than not far from intuitive. Moreover, they are multi-user objects whereby usage requires a high degree of mutual attunement with others who are using the object at the same time. This kind of interaction is tied in with rules and conventions. These rules and conventions are the 'glue' of activity. They allow for the construction of shared meanings and the transposition of certain behaviours from one task-artifact configuration to the next. What if, as occasionally happened in our case of plan construction, group members perceive divergent opportunities? What if one group member perceives the opportunity to contribute simultaneously to the drawing space, a second perceives the opportunity to take turns, and a third perceives the opportunity to distribute roles? The three students will have to reflect on and negotiate their utilisation of the workspace in order to collaborate. Affordances, however, neither account for the role of rules and conventions in how artifacts 
Computer-Supported Collaborative Learning

Therefore, a purposeful connection of agents and artifacts in collaborative activity cannot be explained solely by Gibsonian affordances.

In response to this problem, authors have taken up the notion of affordance beyond 'the classic Gibsonian perception-action loop' (Turner 2005). Reworkings of the concept attempt to 'socialise' affordances (e.g. Costall 1995; Norman 1999; Hutchby 2001) so that they can account for cultural variability, reflexive behaviours and the generalisation of ways of doing. The best-known reworking of affordance in the context of technology is that of Norman $(1988,1999)$. The central idea in his project is that of a "system image" that is made visible in the physical structures of the technical artifact. Through interaction with the artifact, the system image translates into a mental model (1988). Principles of direct perception are hereby combined with those of indirect perception. This combination of direct and indirect perception is achieved through a distinction between perceived and real affordances (Norman 1999). The real affordance is the direct, unlearned affordance, as proposed by Gibson. The perceived affordance is "often more about conventions than about reality" (Norman, p. 124). Other authors have proposed this kind of 'socialisation' of affordance. Costall (1995) and Hutchby (2001), for example, include the possibility of learning affordances from others and of designing them into everyday objects, thus pulling affordance out of the natural and into the cultural realm. To what extent is the original affordance or it's reworking useful for studying collaboration in technological settings?

In the preceding we have identified five premises that adhere to the relational nature of Gibson's theory of affordance: 1) its possible use is relative to the needs of the perceiver; 2) its information is directly available to the perceiver, and is not based on any higher-level cognitive processing; 3) its coupling with the agent is 'natural', and governed by ecological laws; 4) it is translated non-reflectively into action, and 5) it is a fixed property of the perceived stimulus. Although the perception of an action opportunity is relative to - either the ecology or culture of - the agent, the effect of the affordance on behaviour is inherent to the artifact and independent of the behaviour itself. The actions of the agent are, in other words, 'directed' by the affordances that become available via the artifact. This tends towards a stance of technological determinism, and underrates reflective and creative agency.

In terms of activity theory, the affordance explains the agent-artifact connection on the level of operations (Baerentsen and Trettvik 2002). Here, 'operations' are understood as nonconscious and driven by conditions of the action at hand (Leont'ev 1978). This counts for situations wherein agents act non-reflectively and where the interaction between agent and artifact is (or has become) transparent, such as when a button is pushed intuitively to perform some function, or when a set of routinized manipulations are performed on an interface. This does not cover all possible situations. As we pointed out, it does not account for the coordination of action between multiple agents, and it does not explain how 'ways of doing' are transposed from one context to another.

Does the 'socialised', representational extension of affordance provide a viable alternative? The extension combines the principles of direct perception with those of indirect perception, in this way allowing for reflection and reference to rules and conventions. The problem with this is that it creates a conflict with several of the premises that warrant the 
relational nature of the affordance (i.e. premises 2, 3 and 4). This compromises its explanatory power because it is not evident what the affordance explains if it is not understood as part of a direct perception-action loop. One could argue, on the other hand, that the 'socialised' affordances coexist with the Gibsonian affordance, for example by distinguishing between perceived affordances and real affordances, as Norman does (1999). However, then we have to indicate how the principles of direct perception and those of indirect perception interoperate - like in activity theory (Leont'ev 1978). And this requires additional work.

Finally, there is also a methodological challenge: affordance is real and perceivable (Chemero 2003) but it cannot be reduced to properties of either the artifact or the agent (Gibson 1979). It thus becomes a challenge to distinguish empirically influences of either the agent or the artifact.

\section{Structuration}

The second strand of theory that we review originates from sociology, where it was developed in the context of the structure-agency debate. This debate centres on the relation between human agency and societal structures, whereby the challenge is to account for free agency in relation to stability and - experienced - continuity in the reproduction of social practices and institutions. Traditionally, societal structures are looked upon as imposing constraints on the individual. The influence of societal structures is hereby prioritised over human agency. This tendency could lead to determinism. It emphasises the influence of society on social actors rather than the power of these actors to influence and change society (O'Donnell 2001). One influential attempt to overcome the structure-agency problem in sociology is Structuration Theory (Giddens 1986). Like the theory of affordance, structuration theory adopts a relational position, and like the affordance, derivatives of structuration theory have impacted upon technology studies in an attempt to explain the functional relation between human agents and technical artifacts (Orlikowski 1992, 2000; DeSanctis and Poole 1994; Contractor and Seibold 1993; Gouran 1999; Bansler and Havn 2006).

Structuration theory explains how agents produce more or less stable social practices over time and are able to introduce changes in these practices as well. The theory proposes a system wherein social structures are reproduced in an ongoing interaction process of human agents and structural features. It attempts to escape a determinist view on human agency on the basis of four premises. The duality of structure poses that structures are both medium and outcome of the ongoing interaction (premise 1). Structures are seen as a medium for interaction in that they enable and constrain action; at the same time they are the outcome of that interaction, and are recursively implicated through their reproduction (Giddens 1986). Structures in this sense do not refer to physical characteristics of a surface or interface. Rather, they are conceived of as a property of the social system (premise 2). They are not stable entities and do not exist outside action: structures are constantly being formed and reformed in the production and reproduction of practices. Structure exists only "as memory traces, the organic basis of human knowledgeability, and as instantiated in action" (p. 377). An object - a technical artifact - does not contain structures, it contains structural features (premise 3). These structural features make rules and resources available. Structures emerge from the acting of the agent upon the structural features. Structural features allow "the 'binding' of time-space in social systems [making] it possible for discernibly similar social practices to exist across varying spans of time and space and lend them 'systemic' form" 
implicated in the reproduction of social systems" (p. 377). The rules and resources that become available are relative to the agent that acts upon the object (premise 4). Rules are defined as "generalizable procedures applied in the enactment/reproduction of social life" (Giddens 1986, p. 21). These rules can be constitutive or regulative. They relate to the constitution of meaning (signification) or to the sanctioning of modes of social conduct (legitimation). Rules governing signification enable meaningful communication in that they allow the coding and decoding of a symbolic order. Rules governing legitimation allow moral sanctioning. Furthermore, two kinds of resources are distinguished: authorative resources, which refer to power over people, for example physical strength or knowledge, and allocative resources, which refers to control over objects in the material world, such as technical artifacts or real estate. Resources are focused in practice via the application of rules.

Structuration theory explains the agent-artifact connection by means of structures. Structures - the bindings of rules and resources (as in control over people or objects) - are not tied to a specific situation in time or space. They exist only virtually, and may occur in an unpredetermined range of situations. In this way they allow for the reproduction and generalization of technological practices. In structuration theory, the connection of agent and technical artifact emerges with the instantiation of this binding of rules and resources, both of which become available in the technological setting. What does this mean concretely? Let us revisit our case of plan construction in the shared workspace. Remember that the workspace allowed simultaneous contributions to a drawing space, and that taking turns was also possible. Remember also that the students had a history of collaborative plan construction whereby some groups, as a convention, contributed simultaneously to a paper and pen representation of their project plan. In terms of structuration theory, these students deliberately transposed this convention from the 'regular' mode of planning - to contribute simultaneously to the plan - to the new technological setting. The convention to contribute simultaneously became available as a rule in the new setting, and tied to the available mode of control over the drawing space - that is, simultaneous access. This rule/resource set established a functional connection between the students and the technical artifact that realised a certain potential of the technical artefact, relative to, and in line with the students' intentions. The workspace was brought into use by the students through the generalization of rules and resources and a subsequent reproduction of structures. As the group members were knowledgeable of the rules and resources that were available to them, they were capable of fine-tuning their interaction with the artifact and of coordinating their collaboration.

So far this works for our case. The problem with this conception, however, is the understatement of the resistance of the material world and the constraining effect of certain objects and artifacts (Turner 1986; Sewell 1992; Parker 2000). Criticism boils down to the main premise that underlies the duality of structure, namely that the bindings of rules and resources have a virtual existence. Sewell (1992) suggests that virtual rules are not problematic. Rules are associated with what Giddens (1986) calls 'memory traces', and to what Sewell (1992) refers to as 'schemas or procedures'. These rules or schemas can be generalised, that is, transposed or extended to other situations. "To say that schemas are virtual is to say that they cannot be reduced to their existence in any particular practice or any particular location in space and time: they can be actualised in a potentially broad and unpredetermined range of situations" (Sewell, p. 8). The problem lies with the resources, with the notion of virtual control over objects. Particularly problematic is the category of non-human, 'allocative' resources that bind human agency to material objects like a hammer 
or a computer. It is difficult to view such bindings as entirely virtual. Let us return to the case of the shared workspace. What if the workspace would physically resist simultaneous contribution to the project plan in the drawing space? In fact, the workspace can be configured to present a floor-control mechanism that requires group members to take turns in the construction of their plan. When the rule to contribute simultaneously becomes associated with the available mode of control over the drawing space - in that case, turntaking - a non-functional relation between the students and the technical artifact would be established. A feature that requires students to take turns physically resists simultaneous participation, regardless of the students' intentions. When the artifact is configured in this way, simultaneous access as a mode of control over the workspace is simply not available. It is not hard to think of other examples where technical artifacts physically resist certain operations by its users. Control over an artifact is an outcome of social structures only up to certain limits. According to Sewell, the notion of structure is in contradiction with itself: "If structures are virtual, they cannot include both schemas and resources. And if they include both schemas and resources, they cannot be virtual" (p. 10-11). Sewell concludes that structure could be seen as "composed simultaneously of schemas, which are virtual, and of resources, which are actual" (p. 13).

Reworkings of structuration theory have been developed within the organisational sciences, where the aim is to account for the connection of human agency and advanced information technologies in organizations (the so-called meso-level). It appeared that with the introduction of advanced information technologies in these organisational contexts, groups of people 'appropriated' these technologies sometimes in unexpected ways (Orlikowski 1992; DeSanctis and Poole 1994). This led DeSanctis and Poole (ibid.) to argue for a position of soft line determinism, based on structuration concepts. Adaptive structuration theory describes the appropriation of new technology as a process of organisational change that is a result of group interaction. "New social structures emerge as the rules and resources of the technology are appropriated in a given context and reproduced in group interaction over time" (DeSanctis \& Poole, p. 129). In this view, structural features that are carried by the technical artifact make rules and resources available that are relative to the practice in which the technical artifact is introduced. 'Appropriations' of a technology are immediate, visible actions that evidence how these rules and resources reorganize a practice. Adaptive structuration deviates from structuration crucially at the point where the coupling of rule-resource sets to technical artifacts is explained. In fact, the theory does not explain this coupling. Instead, in order to escape a stance of technological voluntarism, DeSanctis and Poole (1994) introduced the notion of "spirit". Technology appropriation is not entirely voluntary, but in accordance with the spirit of the technology. Spirit is the general intent with regard to the values and goals that underlie a set of structural features (DeSanctis and Poole). Again, as with the concept of affordance, the question that arises is to what extent structuration theory can be modified in this way without compromising its explanatory power. To what extent is the theory of structuration or its reworking fit to explain the connection of agents and artifact in the context of collaboration in technological settings?

Structuration, similar to affordance, reflects a relational position on the connection of agent 
agent that interacts with the artifact. But this is where the similarity ends. With structuration, the agent is 'knowledgeable' about rules and resources, and this knowledgeability allows for the generalisation of 'ways of doing' from one context to another. Furthermore, rules and resources are instrumental to the needs of the agent. Structuration proposes a notion of agency in which agents display practical and discursive consciousness (Giddens 1986). Behaviour is not determined by technical-material structures, and human agents may act reflectively and intentionally. Agents may induce changes in the production of structures which, when reproduced, become enduring and result in a transformation of their practice. As we have discussed, there are some fundamental issues: structuration theory overrates the degree of control that people have over material objects and underrates the obduracy of the material world. This is a general problem in radical constructivist theories (Hutchby 2001). Human agency is there often prioritised over material agency. In doing so, structuration ends up at a position of technological voluntarism. The reworking of structuration (DeSanctis and Poole 1994) is also problematic. It neglects its main premise, that is, it does not account for the duality of structure. It simply bypasses the issue. Although the theory may be useful to create a sensibility for the dynamics that are involved in artifact-mediated collaboration, it fails to preserve the explanatory power of the original theory.

In addition, as with affordance, structuration poses a methodological challenge: structures do not exist outside action (Giddens 1986) and they can thus only be studied by looking at ongoing activities, or rather: processes (Sawyer 2002). This makes it difficult to separate the agent and the artifact empirically.

\section{The instrument}

The third strand of theory that we review is known as the theory of instrumental genesis (Rabardel 1995; Rabardel and Bourmaud 2003). Instrumental genesis can be interpreted as a branch of activity theory (Kaptelinin and Nardi 2006). It addresses the connection of human agents and technical artifact(s) through the concept of instrument. An instrument is a heterogeneous entity, composed of part technical artifact and part human agent. The connection of the agent and the artifact emerges from actions and operations that are specified by an activity scheme and performed upon the artifact. The theory proposes a generative model wherein a technical artifact becomes an instrument through developmental transformations of both the artifact and the people who use it (Rabardel 1995; Rabardel and Bourmaud 2003). An instrument can be considered as a functional organ, a mixed unit made up of an artifactual component (an artifact, a fraction of an artifact or a group of artifacts) and a scheme component (in the Piagetian sense of the term: Piaget 1964), comprising one or more associated utilisation schemes that organise the activity. The instrument emerges from a 'double-development movement', relating to the two components - artifact and utilisation scheme: through the application of utilisation schemes agents adapt and give form to the artifact, a process called instrumentalisation; through a process called instrumentation the utilisation schemes themselves are adapted. As already stated, the double-development movement involves adaptations of both the artifact and the utilisation scheme. When an agent is presented with an artifact, this artifact is either assimilated in an existing scheme, referred to as progressive generalisation, or when there is no suitable scheme available, existing schemes are adapted through progressive differentiation (Rabardel 1995). Adaptations of the artifact can be physical and non-physical. The mechanisms that underlie these adaptations are "selection, regrouping, production and institution of functions, deviations and catachresis (MO: originally, "the misuse of a word")" (Rabardel 1995, p. 103). 
By developing utilisation schemes agents develop skills and abilities to operate an artifact, to decide which tasks should be performed with the artifact, and which methods should be applied to perform the task effectively (Kaptelinin and Nardi 2006). A certain utilisation scheme can be applied to a range of artifacts that belong to the same class. Rabardel (1995) gives the example of driving a car. A utilisation scheme that has developed in driving a specific type of car can also be utilised to drive other types of cars. This activity scheme may be applicable to neighbouring or different classes of artifacts. In the case of driving, for example, the utilisation scheme may allow you to drive a whole range of motorised vehicles, depending on the similarities and differences with that one type of car (e.g., manual or automatic transmission). On the other hand, an artifact is liable to fit into a range of utilisation schemes that will attribute it different significations and sometimes different functions (Rabardel 1995; Rabardel and Bourmaud 2003). For example, the same car can be used for driving on motorways as well as in crowded cities.

Let us return to our case of plan construction in the shared workspace. Remember that in this case the three students could contribute simultaneously to construct their plan in the drawing space. Hereto they had to select a card from the notation scheme that was designed to specify parts of their plan, and type in their contribution in that card. Remember also that the students had no prior experience with this type of workspace technology, and that they did have a lot of experience with chat. Possibly due to this experience, it occurred that some groups utilised the workspace from a 'chat-scheme': they interacted with each other in the drawing space through the production of a lot of relatively small contributions at a high pace. The students in these groups submitted different types of contributions to the drawing space: some of them were related to the content of the project plan, some were related to management of the task or social relations. Typically, the larger part of the communication took place via the drawing space, while face-to-face communication was limited. In contrast, the application of what could be called an 'argumentation scheme', a scheme that had developed around argumentative activity whereby students talk and listen in turns, lead to a relatively small amount of elaborate contributions that were produced at a low pace initially by taking turns, and gradually more parallel. With the application of the "chatscheme' the workspace became a different type of instrument as with the application of the 'argumentation scheme'.

The process of instrumental genesis is hierarchically organised. Building on activity theory, Rabardel and Bourmaud (2003) distinguish three 'orientations of mediation': toward the artifact itself, toward the object of the activity, and toward other subjects. These orientations correspond to three classes of utilisation schemes, representing a 'nested' hierarchy. The first type, the usage scheme, refers to a scheme that has the artifact itself as object of activity. This class of schemes comprises elementary utilisation schemes for handling controls or manipulating the interface of a technical artifact. Usage schemes constitute specialised modules, which, in coordination with other schemes, assimilate and mutually adapt to constitute the second type, instrument-mediated action schemes. Instrument-mediated action schemes are oriented towards the object of activity for which the artifact is a means of performance; that is, towards the goal or motive of the 'main' activity. This type of scheme constitutes an instrumental act. Finally, instrument-mediated collective activity schemes specify the actions of a group of users who share an instrument to fulfil a common motive. This type of scheme 
incorporates the coordination of individual actions and integration of their results as a 516 contribution to common goals.

Instrumental genesis builds on Leont'ev's (1978) model of the hierarchical organization of activity and on Engeström's mediational triangle (1987). This allows identification of distinct dimensions in the establishment of the agent-artifact connection: non-conscious operations, goal-directed actions, as well as personal and collective orientations and rules. In this way, utilisation of a technical artifact in collaborative activity can be decomposed and read as a progressive development from personal mastery to collective utilisation (Overdijk 2009). Let us return once more to our case of plan construction in the shared workspace. The students in our case, all first-time users of the workspace, focused initially on the interaction with the workspace in order to learn how to manipulate its controls. In activity terms, their action was oriented towards manipulating the controls of the workspace, whereby the workspace itself was the object of activity and learning how to manipulate its controls was the motive. Once a group member mastered basic acts such as selecting a card from the notation scheme, typing a contribution in it, and submitting it to the drawing space, his or her attention shifted towards the object for which the artifact was a means of performance - that is, plan construction. Conscious goal-directed actions at the level of mastery were then transformed into nonconscious operations. Subsequently, these routinized basic acts - submitting a specific card from the notation with a certain type of contribution - were coupled to a function - for example, having this specific card-type to indicate external constraints on the project plan. This utilisation of the workspace can be characterized as an enactment of action opportunities aimed at the fulfilment of a task-related motive, which makes up a so-called 'instrumental act' (Rabardel and Bourmaud 2003). Within some groups divergent enactments occurred: for example, group members used the notation in different manners such that collaboration was impeded. In these groups, the formulation of rules allowed for coordination of the interaction with the artifact - for example, having all three students using the same type of card to indicate the same type of information, which supported the collaboration.

The instrument (Rabardel 1995), similar to the affordance and structures, is conceptualised as a heterogeneous entity, comprised of a social-behavioural and a technical-material part. This heterogeneity allows a relational conception of technology wherein both human agents and technical artifact have agentic power. Utilisation schemes allow for the introduction of new and creative ways of doing, for the generalisation of 'ways of doing' from one taskartifact configuration to another, as well as for the management and coordination of artifactmediated activity between multiple agents. Building on Piaget's work, Rabardel conceptualises the utilisation scheme as a 'mental representation for action' that has both private and social dimensions. Utilisation schemes develop in a social context, and in collaborative activity they may mutually adapt to form a collective utilisation scheme that coordinates individual actions oriented towards a common goal. Instrumental genesis places the primacy of action with the human agent: the agent acts upon the artifact from his or her intentions, and the artifact becomes 'instrumental' to his or her specific needs. In this respect, the theory of instrumental genesis is more subject-oriented than the affordance. It suggests, for example, that a technical artifact is 'merely a proposal' to the human agent (Rabardel 1995). This statement reflects a voluntarism similar to that of structuration theory: it emphasizes human agency over technical-material structures. This voluntarism appears to be inconsistent with the cognitive constructivism that is evident in the notions of utilisation scheme, scheme adaptation and assimilation. 
From a methodological viewpoint, instrumental genesis describes the agent-artifact connection as a hierarchically organised system whereby each level in the hierarchy has distinct properties. This allows the connection to be decomposed and analysed accordingly.

\section{Discussion}

Studying how collaborative activity takes shape interactionally in the context of technological settings requires us to look into the 'black box' of how technology is brought into use, or rather, how it is attuned to, interacted with, and shaped in various and varied practices. In this article we focused on the establishment and coordination of a purposeful connection of agents and technical artifacts, what we refer to as 'the agent-artifact connection'. In order to contribute to a theoretically grounded conception of this connection we reviewed three relational positions: either through the concept of affordance (Gibson 1979), structures (Giddens 1986) or instrument (Rabardel 1995), technology is seen as a heterogeneous entity that consists of elements of both agent(s) and artifact. We have considered the implications of these relational positions for the study of collaborative learning in technological settings and focused on strengths and weaknesses. Our aim was to assess which of the positions allows us best to describe the agent-artifact connection in collaborative activity and to what extent the positions acknowledge a mutual shaping - the establishment of a connection wherein both agent and artifact have an influence. In the concluding part we discuss the main findings of our comparative review.

In a relational view, a technical artifact carries a potential for action that becomes available when agent and artifact connect. The availability of specific action opportunities is relative to the person(s) who connect(s) with the artifact. But what specific part of the human agent are action opportunities relative to? And what governs the realisation of these opportunities? In Gibson's theory of affordance (1979), opportunities for action are relative to the agent's needs. These opportunities are directly perceived, that is, without the agent being necessarily aware of some form of internal representation. The affordance theory posits that the connection of agent and artifact is 'natural' (Shaw 2003). The connection is not governed by mental representations or cultural conventions, but by ecological laws. Such laws may cover those situations wherein agents interact non-reflectively with the artifacts in their 'natural' environment. They do not explain how people make choices, or how cultural behaviours are appropriated in, reflected upon and transposed over diverse social contexts. Nor do they account for the organisation of collaborative behaviour. In addition to any laws that may or may not be at work, rules and conventions are crucial to explain the collective and cultural dimensions of how artifacts mediate activity (e.g. Miettinen 2001; Engeström 1999). Both structuration theory and instrumental genesis recognise rules and conventions as vehicles for social and cultural organisation of behaviour. These rules and conventions exist in cognitive structures that are a part of the agent (either as memory traces or cognitive schemas). They mediate activity and can be reflected upon, shared and negotiated. Structuration theory (Giddens 1986), however, represents a sociological perspective and does not specify any cognitive or social psychological aspects of the agent-artifact connection. Instrumental genesis, in contrast, allows a detailed analysis of human action through a 'nested' hierarchical model (Rabardel and Bourmaud 2003) based on activity theory (Kaptelinin and Nardi 2006; Engeström 1999). This allows the researcher to take learners' orientations, motivation and abilities into consideration, which is a prerequisite for most CSCL studies. It also allows the researcher to describe the agent-artifact connection as a development from personal mastery of the artifact to a collective utilization (Overdijk 2009). 
Affordances, structures and instruments confer on both agent(s) and artifact some degree of agentic power, or agency. Both human agent and artifact have an influence on the nature of their connection. But how is this agency distributed? The three positions differ in the degree to which they award agentic power to either human agent or artifact. Affordances hold that a technical artifact has real properties that exercise an influence on human behaviour. Furthermore, they hold that this influence is inherent to the artifact and - although its occurrence is relative to the needs of the agent - its nature is essentially independent of the behaviour of the agent. With affordances, human agency is downplayed in favour of material agency. When applied to technology this tends to lead to a stance of technological determinism: 'a displacement of causation from human agency to machines' (Bijker 1995). With structuration theory we find the opposite stance. This theory prioritises human agency over material agency. Instead of behaviour being determined by technical-material structures, human agents act intentionally and creatively with technology. With the suggestion that human agents can control technology according to their intentions, structuration understates the real properties of the technical artifact, which reflects a stance of technological voluntarism. A weaker version of such voluntarism can be found with instrumental genesis.

What are the methodological implications of this? We can contrast the three positions in terms of their ontological claims. A process ontology regards the human agent and the tools and artifacts in his or her environment as inseparable; the two have no meaning outside activity (Sawyer 2002). Human agents and the sociocultural environment within which they are situated can only be studied by looking at ongoing activities, or rather: processes. A systems perspective, in contrast, describes social reality on various levels of complexity, each with its own distinct properties (Van Diggelen 2011). A systems perspective allows an analytical separation of agent and artifact. Both the affordance and structuration theory consider the influence of agent and artifact de facto as inseparable. This inseparability brings about methodological problems (Archer 1995). Influences of either the human agent or the technical artifact become empirically indistinguishable. The theory of instrumental genesis, in contrast, takes on a systems perspective: it describes the agent-artifact connection as a hierarchically organised system whereby each level in the hierarchy has distinct properties. This allows the connection to be decomposed and analysed accordingly: the behavioural scheme component and the artifact component can be distinguished - and decomposed further - from the activity under study, and so can individual and collective orientations in the activity.

\section{Conclusion}

So where does this leave us? The rationale of 'mutual shaping' of agent and artifact posits that the technical artifact shapes the learners' behaviour, and that the learner shapes the technical artifact - or rather, the opportunities that are made available by it. Consequently, one has to take into account this mutual shaping. Each of the three positions we have discussed proposes a relational perspective whereby educational technology emerges from an interaction of learners and technical artifacts and is shaped by both. The challenge is to explain the establishment and coordination of this connection without unnecessarily prioritising the influence of one over the other. In our view, of the three positions, instrumental genesis proposes the most viable approach to this challenge.

Instrumental genesis allows a thorough description of how educational technology develops from the interaction of learners and technical artifacts. It acknowledges the influence of both the learners and the artifact - of both human behaviour and technical 
content, without emphasizing one over the other. It allows one to describe in detail how the agent-artifact connection is established and subsequently managed among multiple collaborating agents. The connection is seen as a hierarchically developed activity system that can be analytically separated. This developmental perspective is very useful for CSCL because distinct elements that constitute and influence the mediated learning activity can be assessed and used for purposes of design. For example:

- On a personal dimension, the physical connection that each single learner entertains with the artifact, or the ability to reflect and make conscious choices based on personal needs, goals and expectations.

- On a collective dimension, coordination and fine-tuning of the interaction with the artifact among multiple learners in order to achieve a common goal.

- On a practice dimension, local norms and conventions that adhere to particular taskartifact configurations.

For many CSCL studies it is relevant to ask to what extent learners' actions are influenced by artifactual constraints and opportunities, and how pre-existing knowledge and experience come into play. For most studies it is relevant to analyze how groups organize and fine-tune their interaction with the artifact in order to collaborate. The theory of instrumental genesis allows such an analysis in a manner that is theoretically and methodologically grounded, whereas the other two relational positions do not.

\section{References}

Archer, M. S. (1995). Realist social theory: The morphogenetic approach. New York: Cambridge University Press.

Baerentsen, K., \& Trettvik, J. (2002). An activity theory approach to affordance. In O. W. Bertelsen, S. Bodker, \& K. Kuuti (Eds.), Proceedings of the second nordic conference on human-computer interaction (pp. 51-60). New York: ACM Press.

Baker, M., Bernard, F.-X., \& Dumez-Féroc, I. (2012). Integrating computer-supported collaborative learning into the classroom: The anatomy of a failure. Journal of Computer Assisted Learning.

Baker, M. J., \& Lund, K. (1997). Promoting reflective interactions in a computer-supported collaborative learning environment. Journal of Computer Assisted Learning, 13, 175-193.

Bansler, J. P., \& Havn, E. (2006). Sensemaking in technology-use mediation: Adapting groupware technology in organizations. Computer Supported Cooperative Work, 15, 55-91.

Bijker, W. (1995). Of bicycles, bakelites, and bulbs: Toward a theory of socio-technical change. Cambridge: MIT Press.

Bonderup Dohn, N. (2009). Affordances revisited: Articulating a Merleau-Pontian view. International Journal of Computer-Supported Collaborative Learning, 4(2), 151-170.

Chemero, A. (2003). An outline of a theory of affordances. Ecological Psychology, 15(2), 181-195.

Contractor, N. S., \& Seibold, D. R. (1993). Theoretical framework for the study of structuring processes in group decision support systems: Adaptive structuration theory and self-organizing theory. Human Communication Research, 19, 528-563.

Costall, A. (1995). Socializing affordances. Theory \& Psychology, 5, 467-481.

Dant, T. (2005). Materiality and sociality. Maidenhead: Open University Press.

DeSanctis, G., \& Poole, M. S. (1994). Capturing the complexity of advanced technology use: Adaptive structuration theory. Organization Science, 5(2), 121-147.

Dillenbourg, P., \& Tchounikine, P. (2007). Flexibility in macro-scripts for computer-supported collaborative learning. Journal of Computer Assisted Learning, 23(1), 1-13.

Dwyer, N., \& Suthers, D. D. (2006). Consistent practices in artifact-mediated collaboration. International Journal of Computer-Supported Collaborative Learning, 1(4), 481-511.

Engeström, Y. (1987). Learning by expanding: An activity-theoretical approach to developmental research. Helsinki: Orienta-Konsultit. 
Engeström, Y. (1999). Activity theory and individual and social transformation. In Y. Engeström, R. Miettinen, \& R.-L. Punamäki (Eds.), Perspectives on activity theory (pp. 19-38). Cambridge: Cambridge University Press.

Fischer, F., Kollar, I., Mandl, H., \& Haake, J. M. (2007). Scripting computer-supported collaborative learning: Cognitive, computational and educational perspectives. New York: Springer.

Gaver, W. (1991). Technology affordances. Proceedings of CHI 1991, 79-84.

Gaver, W. (1996). Affordances for interaction: The social is material for design. Ecological Psychology, 8(2), 111-129.

Gibson, J. J. (1979). The ecological approach to visual perception. Boston: Houghton Mifflin.

Giddens, A. (1986). The constitution of society: Outline of the theory of structuration. Cambridge: Polity Press.

Gouran, D. S. (1999). Communication in groups: The emergence and evolution of a field of study. In L. R. Frey, D. S. Gouran, \& M. Scott Poole (Eds.), The handbook of group communication theory and research (pp. 3-36). London: Sage Publishers.

Hartson, H. R. (2003). Cognitive, physical, sensory, and functional affordances in interaction design. Behaviour \& Information Technology, 22(5), 315-338.

Hutchby, I. (2001). Technologies, texts and affordances. Sociology, 35, 441-456.

Jermann, P., \& Dillenbourg, P. (2003). Elaborating new arguments through a CSCL scenario. In J. Andriessen, M. Baker, \& D. Suthers (Eds.), Arguing to learn: Confronting cognitions in computer-supported collaborative learning environments (pp. 205-226). Amsterdam: Kluwer Academic Publishers.

Jones, C., Dirckinck-Holmfeld, L., \& Lindström, B. (2006). A relational, indirect, meso-level approach to CSCL design in the next decade. International Journal of Computer-Supported Collaborative Learning, $1(1), 35-56$.

Kaptelinin, V., \& Nardi, B. (2006). Acting with technology: Activity theory and interaction design. Cambridge: MIT Press.

Kirschner, P. A., Strijbos, J.-W., Kreijns, K., \& Beers, P. J. (2004). Designing electronic collaborative learning environments. Educational Technology Research and Development, 52(3), 47-66.

Kollar, I., Fischer, F., \& Hesse, F. W. (2006). Collaboration scripts - a conceptual analysis. Educational Psychology Review, 18, 159-185.

LeBaron, C. (2002). Technology does not exist independent of its use. In T. Koschmann, R. Hall, \& N. Miyake (Eds.), CSCL2: Carrying forward the conversation (pp. 433-440). Mahwah: Lawrence Erlbaum Assoc.

Leont'ev, A. N. (1978). Activity, consciousness, and personality. Englewood Cliffs: Prentice Hall.

MacKenzie, D. A., \& Wajcman, J. (1985). The social shaping of technology: How the refrigerator got its hum. Milton Keynes: Open University Press.

Miettinen, R. (2001). Artifact mediation in Dewey and in cultural/historical activity theory. Mind, Culture and Activity, 8(4), 297-308.

Muller Mirza, N., Tartas, V., Perret-Clermont, A., \& de Pietro, J. (2007). Using graphical tools in a phased activity for enhancing dialogical skills: An example with Digalo. International Journal of ComputerSupported Collaborative Learning, 2(2-3), 247-272.

Norman, D. (1988). The psychology of everyday things. New York: Basic Books.

Norman, D. (1999). Affordance, conventions, and design. Interactions, 6(3), 38-43.

O'Donnell, M. (2001). Classical and contemporary sociology: Theory and issues. London: Hodder and Stoughton.

Oliver, M. (2011). Technological determinism in educational technology research: Some alternative ways of thinking about the relationship between learning and technology. Journal of Computer Assisted Learning, 27, 373-384.

Orlikowski, W. J. (1992). The duality of technology: Rethinking the concept of technology in organizations. Organization Science, 3, 398-427.

Orlikowski, W. J. (2000). Using technology and constituting structures: A practice lens for studying technology in organizations. Organization Science, 11(4), 404-428.

Overdijk, M. (2009). Appropriation of technology for collaboration: From mastery to utilization. Unpublished doctoral dissertation: Utrecht University.

Overdijk, M., \& Van Diggelen, W. (2008). Appropriation of a shared workspace: Organizing principles and their application. International Journal of Computer-Supported Collaborative Learning, 3, 165-192.

Parker, J. (2000). Concepts in the social sciences: Structuration. Buckingham: Open University Press.

Piaget, J. (1964). Six etudes de psychologie [Six studies of psychology]. Paris: Denoël.

Rabardel, P. (1995). Les hommes et les technologies: Approches cognitives des instruments contemporains [Man and technology: cognitive approaches and contemporary instruments]. Paris: Armand Colin. 
Rabardel, P., \& Bourmaud, G. (2003). From computer to instrument system: A developmental perspective. Interacting with Computers, 15(5), 665-691.

Rappert, B. (2003). Technologies, texts and possibilities: A reply to Hutchby. Sociology, 37, 565-580.

Sawyer, R. K. (2002). Unresolved tensions in sociocultural theory: Analogies with contemporary sociological debates. Culture \& Psychology, 8(3), 283-305.

Sewell, W. H. (1992). A theory of structure: Duality, agency, and transformation. The American Journal of Sociology, 98(1), 1-29.

Shaw, R. (2003). The agent-environment interface: Simon's indirect or Gibson's direct coupling? Ecological Psychology, 15(1), 37-106.

Stahl, G., \& Hesse, F. (2006). ijCSCL - a journal for research in CSCL. International Journal of ComputerSupported Collaborative Learning, 1(1), 3-8.

Stahl, G., \& Hesse, F. (2010). Beyond folk theories of CSCL. International Journal of Computer-Supported Collaborative Learning, 5(4), 354-359.

Stahl, G., Koschmann, T., \& Suthers, D. (2006). Computer-supported collaborative learning: An historical perspective. In R. K. Sawyer (Ed.), Cambridge handbook of the learning sciences (pp. 409-426). Cambridge: Cambridge University Press.

Stoffregen, T. A. (2004). Breadth and limits of the affordance concept. Ecological Psychology, 16(1), 79-85.

Suthers, D. D. (2006). Technology affordances for intersubjective meaning making: A research agenda for CSCL. International Journal of Computer-Supported Collaborative Learning, 1, 315-337.

Turner, J. H. (1986). The theory of structuration. The American Journal of Sociology, 19(4), 969-977.

Turner, P. (2005). Affordance as context. Interacting with Computers, 17(6), 787-800.

Van Diggelen, W. (2011). Changing face-to-face communication: Collaborative tools to support small-group discussions in the classroom. Groningen: Groningen University. Unpublished doctoral dissertation. 


\section{AUTHOR QUERIES}

\section{AUTHOR PLEASE ANSWER ALL QUERIES.}

Q1. Please check article title if captured and presented correctly.

Q2. Please check author group if captured and presented correctly.

Q3. Please check affiliations if captured and presented correctly

Q4. Please check captured corresponding author and corresponding affiliation if appropriate.

Q5. Please check captured sections 1 and 2 in the body, if captured correctly.

Q6. Bernard \& Baker, 2012 has been changed to Baker et al. 2012. Please check if appropriate.

Q7. In press was changed to 2012 and its citation, please check if appropriate.

Q8. Please check captured book title and city for this reference, if appropriate.

Q9. Please check captured bib comments for this reference, if appropriate. 